\title{
Recent insights into the linked deposition, deformation, and dissolution of Aptian (Lower Cretaceous) evaporites on the Sao Paulo Plateau, Santos Basin, offshore Brazil
}

\author{
CHRISTOPHER AIDEN-LEE JACKSON ${ }^{1}$, CLARA
}

RODRIGUEZ $^{2}$, MICHAEL HUDEC ${ }^{3}$, REBECCA BELL ${ }^{1}$, ATLE ROTEVATN $^{4}$, LEONARDO PICHEL ${ }^{4}$, TIM DOOLEY ${ }^{3}$ AND MALCOLM FRANCIS ${ }^{5}$

${ }^{1}$ Imperial College

${ }^{2}$ Petronas

${ }^{3}$ University of Texas at Austin

${ }^{4}$ University of Bergen

${ }^{5}$ Retired

Presenting Author: C.jackson@imperial.ac.uk

In this talk we will outline new insights into the deposition, deformation, and dissolution of Aptian evaporites in the Santos Basin, with specific focus on the São Paulo Plateau. These new insights were gained by integrating: (i) 3D seismic and borehole data - to characterise the salt structure, composition, and kinematics; (ii) physical modelling - to test the mechanical plausibility and basis of intrasalt kinematic models; (ii) structural restorations and flexural backstripping (reverse basin modelling) - to constrain the timing and patterns of salt-related deformation and impact on crustal structure. We show that the pre-rift geometry of the São Paulo Plateau influence spatial variations in evaporite composition, with anhydrite being relatively common on relict, rift-related highs, and halite and Mg-rich salt being volumetrically more significant in flanking lows. Subsequent flow resulted in a range of complex intrasalt structures, including reverse shear zones, feeders, flaps, and sheets. Borehole data suggest that these structures locally formed due to compositionally-driven, Rayleigh-Taylor (R-T) overturn within growing diapirs, especially in parts of the basins characterised by pronounced vertical (stratigraphic) changes in intrasalt composition and density structure. Sometime in the Paleogene after the main phase of diapirism, the crests of mature diapirs were dissolved occurred much of the São Paulo Plateau, the pattern and style of which was related to the primary intrasalt lithology. Flat, halite-dominated diapirs crests are mainly characterised by up to $100 \mathrm{~m}$ tall, sub-circular mounds, likely comprising insoluble evaporite. In contrast, rugose, evaporiteinterbedded diapir crests are mainly characterised by up to $100 \mathrm{~m}$ deep, oval-to-circular sinkholes formed above more soluble evaporite units (e.g. Mg-rich salts). Up to $60 \mathrm{~m}$ tall breccia pipes, capped by collapse-related sinkholes, formed within the overburden above both flat and rugose diapir crests. Reversebasin modelling suggests salt dissolution occurred in a fully submarine environment in water depths of $1900 \mathrm{~m}$ ( $\pm 100 \mathrm{~m})$. In summary, this talk demonstrates a direct link between the primary intrasalt stratigraphic heterogeneity, and the style and sequence of subsequent deformation and dissolution. 